\title{
Characterization of Campylobacter phages including analysis of host range by selected Campylobacter Penner serotypes Vinni Mona Hansen ${ }^{\dagger 1}$, Hanne Rosenquist ${ }^{\dagger 1}$, Dorte Lau Baggesen ${ }^{\dagger 1}$, Stanley Brown ${ }^{\dagger 2}$ and Bjarke Bak Christensen* ${ }^{* 1}$
}

\author{
Address: ${ }^{1}$ Department of Microbiology and Risk Assesment, National Food Institute, Soeborg, Denmark and ${ }^{2}$ Department of Molecular Biology, \\ Copenhagen University, Copenhagen, Denmark \\ Email: Vinni Mona Hansen - vmh@arbejdsmiljoforskning.dk; Hanne Rosenquist - hrq@food.dtu.dk; Dorte Lau Baggesen - dlb@food.dtu.dk; \\ Stanley Brown - stanley@nano.ku.dk; Bjarke Bak Christensen* - bbc@food.dtu.dk \\ * Corresponding author †Equal contributors
}

Published: 18 October 2007

BMC Microbiology 2007, 7:90 doi:10.1186/147/-2180-7-90
Received: 21 December 2006

Accepted: 18 October 2007

This article is available from: http://www.biomedcentral.com/I47/-2/80/7/90

(C) 2007 Hansen et al; licensee BioMed Central Ltd.

This is an Open Access article distributed under the terms of the Creative Commons Attribution License (http://creativecommons.org/licenses/by/2.0), which permits unrestricted use, distribution, and reproduction in any medium, provided the original work is properly cited.

\begin{abstract}
Background: The predominant food borne pathogen in the western world today is Campylobacter. Campylobacter specific bacteriophages (phages) have been proposed as an alternative agent for reducing the burden of Campylobacter in broilers. One concern in relation to phage biocontrol is the narrow host range often displayed by phages. To identify the potential of phages as a Campylobacter reducing agent we needed to determine their infectivity on a panel of isolates representing the Campylobacter strains found in broilers as well as humans.
\end{abstract}

Results: In this study, Campylobacter phages were isolated from the intestines of broilers and ducks and from abattoir sewage. Twelve phages were investigated to determine their ability to infect the Campylobacter Penner serotypes commonly present in Danish poultry and patients with campylobacteriosis. A total of $89 \%$ of the Campylobacter jejuni strains and 14\% of the Campylobacter coli strains could be infected by at least one of the bacteriophages. The majority of the phages infected the most common serotypes in Danish broilers (O:I,44; O:2; O:4-complex), but showed limited ability to infect 21 of the less frequent Campylobacter serotypes. Pulse field gel electrophoresis (PFGE) and restriction endonuclease analysis (REA) were used to characterize the phage genomes. Three categories of bacteriophages were observed. I: a genome size of $\sim 194 \mathrm{~kb}$ and refractory to digestion with Hhal; II: a genome size of $\sim 140 \mathrm{~kb}$ and digestible by Hhal; and III: a genome size undeterminable in PFGE. The categorization of the phages correlated with the host range patterns displayed by the phages. Six phages were subjected to transmission electron microscopy (TEM). They all belonged to the family of Myoviridae.

Conclusion: We have characterized and identified the host range of 12 Danish Campylobacter phages. Due to their ability to infect the majority of the common serotypes in Denmark we suggest the phages can become an effective agent in the effort to reduce the incidence of campylobacteriosis in Denmark. This study provides the basis for future experiments in Campylobacter phages and knowledge for the selection of Campylobacter phages for biocontrol in broilers. 


\section{Background}

Campylobacter is a zoonotic pathogen naturally present in the gastrointestinal tract of many domestic animals and pets [1-4]. In Denmark and in many other developed countries, Campylobacter enteritis is the predominant food borne disease [3]. In Denmark, fresh poultry meat has been identified as the main risk factor for human campylobacteriosis [5]. Consumption of undercooked chicken meat and cross contamination with ready-to-eat foods through improper food handling contributes to human infections [6,7]. C. jejuni is the predominant species in broilers as well as in humans [8]. A Danish surveillance study comparing Campylobacter species in humans, domestic animals and food products revealed that $93 \%$ of the speciated isolates from humans were C. jejuni. Among these, $63 \%$ belonged to the Penner serotypes O:1,44, O:2, and $\mathrm{O}: 4 \mathrm{C}$ (4-complex), that likewise were the most frequent serotypes isolated from broilers (46\%), cattle (57\%), and food (49\%) [9]. C. coli constituted 6.5\% of the human isolates. This species was occasionally found in poultry but predominantly found in pigs [9]. Strategies to improve food safety by reducing the risk of Campylobacter include efforts in the primary production, at the slaughter line, and at the consumer level [3]. Risk assessments have suggested that one of the most efficient ways to reduce the incidence of campylobacteriosis is through methods that reduce numbers of Campylobacter in poultry meat $[10,11]$. One such method is freezing, which has been shown to reduce the number of viable Campylobacter cells approximately 100 fold [12-14]. Unfortunately, frozen products do not suit the consumer demands for chilled products, that are ready to cook without thawing. Therefore, other methods to control the level of Campylobacter in the final product are required.

One potential strategy for controlling bacterial pathogens in food production is the application of virulent phages, viruses that can kill bacterial cells $[15,16]$. The phage reproduces inside the bacterial cell and cause it to lyse releasing progeny phage into the environment. Phages possess several advantages compared to traditional antibiotics, including self-replication/self-limitation and selective modification of the bacterial flora [15]. Most bacterial species are challenged by their own specific bacteriophages that seldom cross species barriers. Campylobacter phages have been recovered from environments harboring Campylobacter [17-20] and seem to be a natural part of the intestinal flora of Campylobacter colonized broilers [21-23]. To reduce numbers of Campylobacter in chicken meat, the bacteriophages may be orally administrated to the broilers before slaughter or applied onto the meat after slaughter. Studies have shown that the use of bacteriophages as biocontrolling agents significantly reduced Campylobacter and Salmonella shedding from live birds and contamination on chicken skin [24-30].
One concern in relation to commercial use of bacteriophages in the chicken production is the narrow host range displayed by these viruses [15]. The host range of Campylobacter phages has previously been investigated on strains representing the phage types of the United Kingdom typing scheme, phage typed reference strains of human origin, and strains isolated during fieldwork for characterization $[20,21,23,28]$. Even though the work has described phages by grouping them into different classes of lytic spectra and has reported qualitative information about the phages capability of killing Campylobacter strains, a study combining epidemiological studies on Campylobacter and phage host range has been missing.

The aim of this study was to isolate and characterize Campylobacter specific phages from the Danish poultry production (broilers and ducks) and investigate their effectiveness against the Penner serotypes that are commonly present in poultry and humans in order to be able to select effective phages for future biocontrol.

\section{Results \\ Isolation of phages}

A total of 312 samples were collected and analyzed for Campylobacter phages. As shown in table 1, 222 samples were isolated from broiler intestines. Of these samples, $62,6 \%$ originated from flocks that were recorded by the Danish Campylobacter surveillance program to be Campylobacter positive. For the remaining samples (ducks and abattoir samples) the flock status where not known. Table 1 shows that the type of poultry (broiler or duck) had greater influence on the phage isolation rate than sample type (intestine or abattoir). The isolation rate from broiler samples was approximately 3\%. However, phages could be isolated from approximately $50 \%$ of the duck samples, making ducks the best source for Campylobacter phages in this study. Of the four phages isolated from the intestine of broilers with known flock status, one phage (F14) was isolated from a flock with a Campylobacter negative status and the remaining 3 from flocks with a positive status. For initial phage isolation, Campylobacter strains NCTC 12662 and 1447 were used as hosts for all 312 samples. Toward the end of the Campylobacter season in Denmark (late Septemper), strain NCTC 12658 was added as an additional isolation host for the last two collected samples, and phages were recovered from both of these. NCTC 12662 supported the isolation of $80 \%$ of the phages. Strain 1447 supported the isolation of one phage, F336, which was isolated from the same sample as phage F326 (Table 1). It was found that some of the phages, isolated from three independent broiler abattoir samples, were unstable during storage, therefore they were excluded from further investigation. 
Table I: Overview of investigated samples and isolated phages

\begin{tabular}{|c|c|c|c|c|}
\hline Origin of samples & Enrichment & $\begin{array}{c}\text { Number of } \\
\text { investigated samples }\end{array}$ & $\begin{array}{l}\text { Number of phage } \\
\text { positive samples }\end{array}$ & Names of isolated phages (Isolation strain) \\
\hline \multirow[t]{4}{*}{ Broiler intestine } & No & 222 & 4 & FI4 (NCTC I2662) \\
\hline & & & & FI98 (NCTC 12662) \\
\hline & & & & F34I (NCTC I 2658) \\
\hline & & & & F346 (NCTC I 2658) \\
\hline \multirow[t]{4}{*}{ Duck intestine } & No & 7 & 3 & F287 (NCTC 12662) \\
\hline & & & & F325 (NCTC I 2662) \\
\hline & & & & F326 (NCTC I 2662) \\
\hline & & & & F336 (Lab. no. I 447) \\
\hline \multirow[t]{3}{*}{ Broiler abattoir } & Yes & 80 & 5 & F267 (NCTC I 2662) \\
\hline & & & & F268 (NCTC 12662) \\
\hline & & & & Three isolates were unstable under lab conditions (NCTC 12662). \\
\hline \multirow[t]{2}{*}{ Duck abattoir } & Yes & 3 & 2 & F207 (NCTC 12662) \\
\hline & & & & F303 (NCTC 12662) \\
\hline
\end{tabular}

\section{Molecular characterization and transmission electron microscopy}

The phages were analyzed by PFGE and REA to determine genome size and sensitivity towards digestion with the restriction enzyme HhaI. Eventhough a signal were visible in the F14 well no DNA were observed to enter the the pulsed field gel, which precluded estimation of the genome size. A prolonged running time of $12 \mathrm{~h}$ did not change the observed outcome for phage F14. Phage F325 displayed the largest genome ( $194 \mathrm{~kb})$ and the remaining phages had each an estimated genome size of approximately $140 \mathrm{~kb}$ (Table 2). REA showed that the DNA isolated from phage F325 could not be digested with HhaI. An attempt to digest the expected F14 DNA with HhaI was unsuccesful, since DNA bands still were absent in the gel (Figure 1). All phages with a genome size of $\sim 140 \mathrm{~kb}$ could be digested with HhaI. Each phage displayed between 2-5 strong bands in the PFGE ranging in size between 9-50 kb (Figure 1). The REA allowed for categorizing the $140 \mathrm{~kb}$ phages into five different restriction patterns (a-e) (Table 2).
Six representatives of the isolated phages were further subjected to morphological studies by transmission electron microscopy (TEM). All had icosahedral heads and contractive tails, which place them into the family of Myoviridae [31] (Figure 2). The morphology and sizes of the selected phages were not significantly different from each other. The length of the phages was approximately 190 $\mathrm{nm}$ and the average diameter of the phage heads was approximately $84 \mathrm{~nm}$.

\section{Analysis of phage host range}

The host range was investigated by the selected Campylobacter panel presented in Table 3. The C. jejuni serotypes most prevalent among human clinical isolates and broilers in Denmark were each represented by $4-5$ strains, and is referred to as the common serotypes. A selection of other serotypes were represented by one strain each, and are referred to as the less common serotypes. In total the phages were tested on 24 different serotypes of which seventeen were $C$. jejuni and seven were $C$. coli. Of the $C$. jejuni strains tested in spot test $89 \%$ could be lysed by at least one of the phages, whereas only $14 \%$ of the $C$. coli strains could be lysed. The phages examined were gener-

Table 2: Phage catagories based on phage genome size and Hhal restriction patterns

\begin{tabular}{clll}
\hline Category & Genome size & Hhal Pattern (figure I) \\
\hline I & $\sim 194 \mathrm{~Kb}$ & Uncut & F325 * \\
II a & $\sim 140 \mathrm{~Kb}$ & 5 bands & F34I *, F346 \\
II b & $\sim 140 \mathrm{~Kb}$ & 5 bands +2 weak bands & F336 * \\
II c & $\sim 140 \mathrm{~Kb}$ & 4 bands & FI98 * \\
II d & $\sim 140 \mathrm{~Kb}$ & 3 bands & F287 , F326, F303* \\
II e & $\sim 140 \mathrm{~Kb}$ & 2 bands + I weak band & F207, F267 , F268 \\
III & ND* & ND & \\
\end{tabular}

Phage used in figure I to illustrate the restriction pattern of the REA groups.

* Phages studied by TEM.

\#ND, Not Determined 


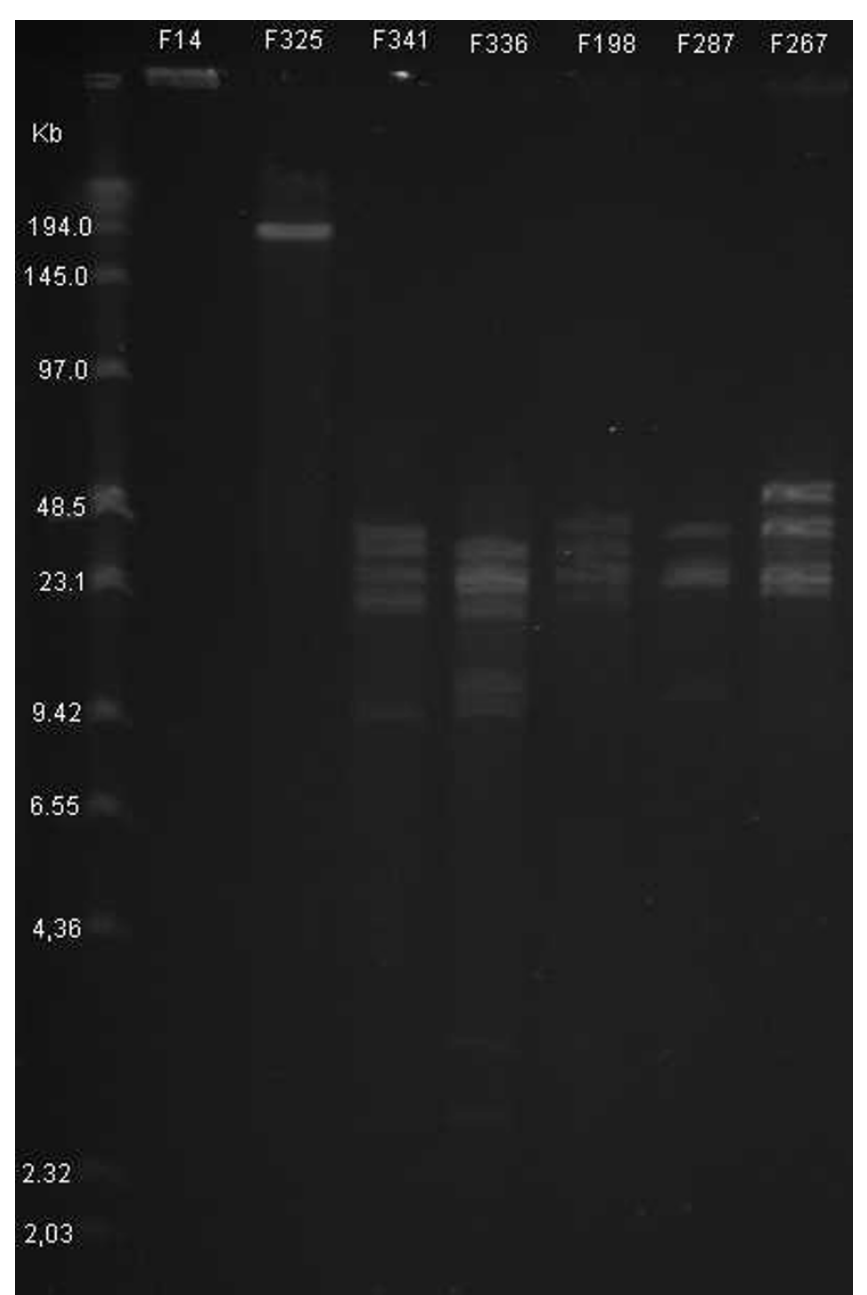

\section{Figure I}

Hhal treated genomes of phages representing the 7 REA group. The DNA bands of phages treated with Hhal are displayed in lane 2-8. The genome of FI4 does not display any DNA bands in lane 2 whereas the genome of F325 display a single band of DNA in lane 3 due to it being refractory to Hhal degestion. The next 5 lanes represent from the left to the right the Hhal restriction patterns of the $140 \mathrm{~Kb}$ phages (group II a-e). Concatemer (New England Biolabs, \#N0350S) is seen in the first lane.

ally well suited for infecting the Campylobacter strains within the serotypes O:1,44, O: 2 and O:4C, but showed less virulent towards the other $C$. jejuni serotypes tested, with exception of serotype $5 \mathbf{j}$ (isolation strain NCTC 12662 ) and serotype 23,36 (strain 81-176) that could be eliminated by 10 and 5 phages, respectively. The widest phage host range was achieved by phage F14, which affected 21 of the 34 tested Campylobacter strains, or 12 of the 24 serotypes. Phage F325 had a diverging host range by being most effective in eliminating the Campylobacter strains different from the O:1,44; O:2 and O:4C serotypes.

\section{Discussion}

Broilers have for other investigators been a fertile source for Campylobacter phages [21-23,28]. In this study Campylobacter phages were isolated much more frequently from ducks than from broilers, indicating that our method was best suited for the former purpose. Several factors can influence the harvest of phages from a particular source. The choice of host is important, since the narrow host range characteristic of most phages can cause them to remain undetected in the screening process. To overcome this obstacle, the C. jejuni strain NCTC 12662, known from the British phage typing system to be sensitive towards a broad range of phages [32], was chosen as a host in this study. Even though the NCTC 12662 strain, with regard to Penner serotype, is not common in the Danish broiler production, most of the isolated phages were detected by this strain [9]. However, the frequency of phage isolation from broilers was lower than previously reported from the United Kingdom [20]. The two other Campylobacter strains used for phage isolation (1447 (serotype O:4C) and NCTC 12658 (serotype O:1,44)) represent common serotypes in Danish poultry. However, although all samples were screened on strain 1447, only one phage was isolated. This is surprising since 1447 proved sensitive to most of the phages. Two samples were screened for phages on NCTC 12658, and phages were isolated from both, indicating that an extended use of NCTC 12658 possibly would have resulted in more isolated phages. Unfortunately, this strain was only included in the last two samples. Finally it should be emphasized that only $62,6 \%$ of the total investigated broiler flocks were Campylobacter positive. This is likely to have had a negative impact on the quantity of phages isolated, since presence of a phage depends on the presence of a host in the environment.

Our investigation, as well as results reported by other investigators indicate that a genome size of $\sim 140 \mathrm{~kb}$ is common for Campylobacter phages, even though Campylobacter phages with genomes ranging from $110 \mathrm{~kb}$ to 320 $\mathrm{kb}$ have also been described [20,21,23,33]. Despite several attempts, phage F14 was the only phage that failed to provide DNA bands in this study, and thus the genome size could not be determined for this phage. Unfortunately, we have not been able to clarify the reasons for this result. A signal, which could be due to the presence of nucleic acid or proteins, could be observed in the F14 well after running (Figure 1). However, if this were DNA we would expect some DNA movement into the gel, irrespective of genome size of the phage DNA. We propose that the result can be due to lack of phage capside degradation during the preparation, which would result in a lack of free DNA in the well. It should be noted that Campylobacter phages that are unable to produce visible DNA 


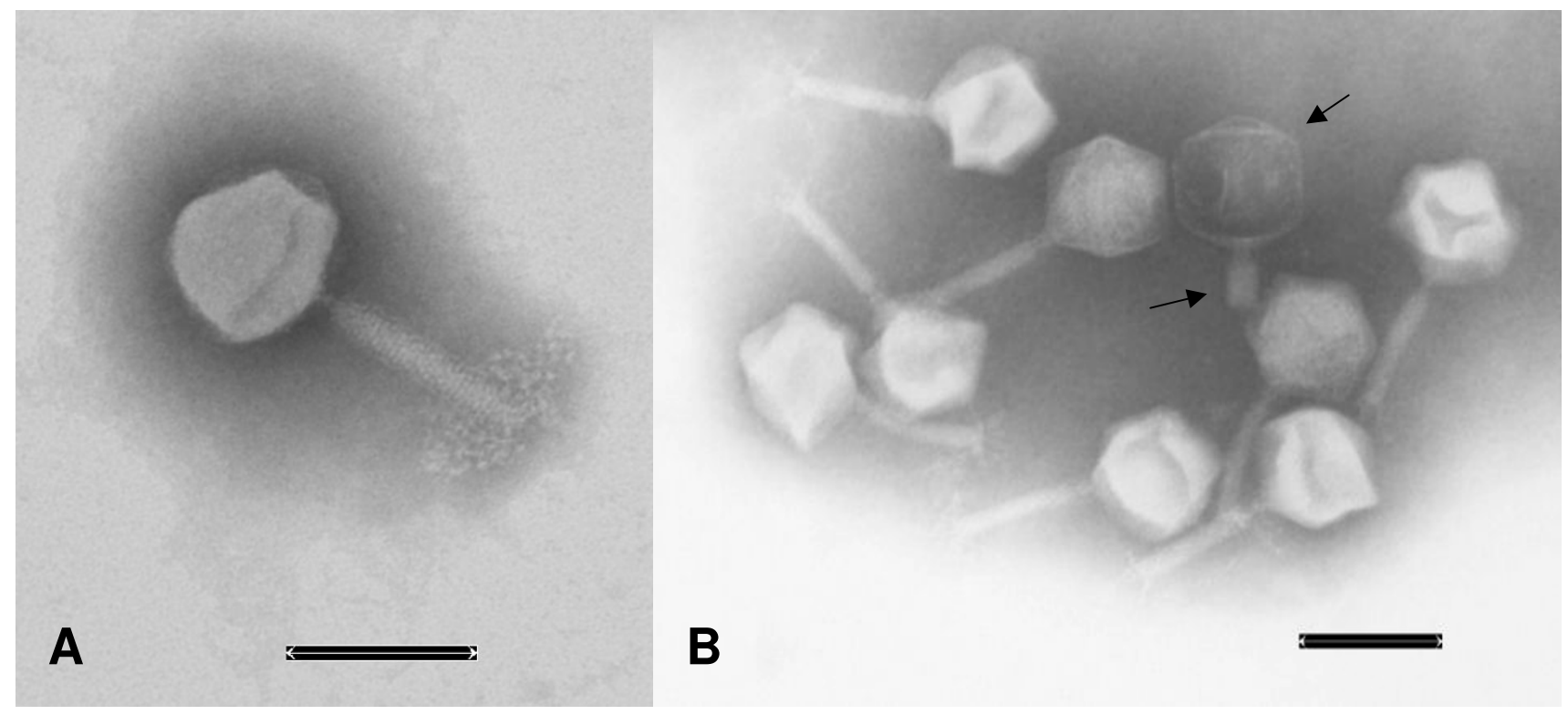

Figure 2

Electron microscope images of FI4 and F336. Image A display a FI4 phage. Image B display several F336 phages. The phage marked by arrows has a contracted tail and a black head, which show that its DNA has been liberated. The lower part of the tail is broken of. The Scale bars in both pictures are $0.1 \mu \mathrm{m}$.

bands have previously been described by Atterbury and co-workers [20].

Based on genome size and REA the phages were divided into three categories. I: Phages with genome size of $\sim 194$ $\mathrm{kb}$ and refractory to digestion with HhaI (F325); II: Phages with genome size of $\sim 140 \mathrm{~kb}$ and digestible by HhaI (F198, F207, F267, F268, F287, F303, F326, F336, F341 and F346,); and III: phage genome undetectable in the PFGE (F14). Phages within each of these categories also displayed considerable differences in Campylobacter host range. The category I phage infected mainly the less common serotypes in Danish poultry, category II phages mainly infected the common serotypes $\mathrm{O}: 1,44 ; \mathrm{O}: 2$, $\mathrm{O}: 4 \mathrm{C}$, and finally the category III phage had a broader host range and infected both strains with common serotype and some of those with a less common serotype. The $\sim 140 \mathrm{~Kb}$ phages digested by HhaI could be further classified into five groups having different REA patterns (a-e). There were no indications of special band patterns being connected to a particular source of isolation. All together we can distinguish between seven types of phages within the twelve isolated phages.

TEM analysis of six phages, each representing one of the types of phage found in this study, showed that the phages all belonged to the family Myoviridae and were of the same size as previously reported for Campylobacter phages $[20,21,28,33]$.

The narrow host range often displayed by bacteriophages has been emphasized as an advantage in phage therapy, compared to chemical antibiotics, due to the limited adverse effect on the natural bacteria population [15]. On the other hand, a phage or a cocktail of phages marketed for commercial use should at least reduce the majority of the species to be controlled. The host range of category II and III phages reveals that they have potential to infect and lyse the Penner serotype O:1,44; O:2 and O:4C. A product aimed at these serotypes will potentially be capable of reducing the Campylobacter infections in approximately $60 \%$ of the infected broiler flocks in Denmark $[8,9]$. In laboratory studies it is possible to reduce C. jejuni infections in broilers by $1-5 \operatorname{logs}[28,30]$. This is a reduction that can cause a considerable decrease in human infections $[10,11]$. It will be possible to enhance the host range by producing a mixture of several phages, for example by mixing phages from each of the three categories mentioned above.

Coward et al. [34] have suggested that phage sensitivity in Campylobacter strains might in some cases be connected to the capsular polysaccharide (CPS) of the cell, which also is the serotypic determinant of the Penner heat-stable serotyping system [35]. In our study there seem to be 
Table 3: Phage host range investigated by spot test

\begin{tabular}{|c|c|c|c|c|c|c|c|c|c|c|c|c|c|c|}
\hline \multirow[b]{2}{*}{ Bact. nr. } & \multirow[b]{2}{*}{ Source } & \multirow[b]{2}{*}{ Serotype and subspecies } & \multicolumn{12}{|c|}{ Reaction of spot test* } \\
\hline & & & $\mathrm{FI} 4$ & FI98 & F207 & F267 & F268 & F287 & F303 & F325 & F326 & F336 & F34I & F346 \\
\hline NCTC 12658 & $\mathrm{nk}^{\wedge}$ & $1,44 \#$ & + & + & + & + & + & + & + & - & + & + & + & + \\
\hline 2486 & Human & $\mathrm{I}, 44 \#$ & + & + & - & + & + & + & + & - & + & + & - & - \\
\hline 2955 & Chicken & $1,44 \#$ & + & + & + & + & + & + & + & + & + & + & - & - \\
\hline $104-733$ & Chicken & $1,44^{\#}$ & + & - & - & + & + & + & + & - & - & + & + & + \\
\hline 11.168 & Human [36] & $2 \#$ & + & - & - & - & - & - & - & - & - & + & + & + \\
\hline 1677 & Chicken & $2^{\#}$ & + & + & - & - & - & + & + & - & - & + & + & + \\
\hline 2453 & Food & $2^{\#}$ & + & + & - & - & + & + & + & - & + & + & + & + \\
\hline 2466 & Chicken & $2^{\#}$ & + & + & - & - & + & + & + & - & + & + & + & + \\
\hline 3024 & Human & $2 \#$ & - & + & - & + & + & + & + & - & + & + & + & + \\
\hline 1590 & Human & $3 \#$ & + & + & + & + & + & + & + & - & + & + & - & - \\
\hline | 447 & Chicken & $4 c^{\# \sim}$ & + & + & + & + & + & - & + & - & - & + & + & + \\
\hline 2467 & Chicken & $4 c^{\# \sim}$ & + & + & + & + & + & + & + & - & + & + & + & + \\
\hline 2469 & Chicken & $4 c^{\# \sim ~}$ & + & + & - & - & - & - & - & - & - & - & + & + \\
\hline $247 \mid$ & Chicken & $4 c^{\# \sim}$ & + & + & + & + & + & + & + & - & + & + & + & - \\
\hline NCTC 12662 & $\mathrm{nk}^{\wedge}$ & $5 j^{\#}$ & + & + & + & + & + & + & + & + & + & + & - & - \\
\hline 1674 & Chicken & $6,7 \#$ & - & - & - & - & - & - & - & - & - & - & - & - \\
\hline 2481 & Chicken & $\mathrm{II} \#$ & - & - & - & - & - & - & - & + & - & - & - & - \\
\hline 3148 & Human & $12^{\#}$ & - & - & - & - & - & - & - & + & - & + & - & - \\
\hline 2464 & Chicken & $18 \#$ & - & - & - & - & - & - & - & - & - & - & - & - \\
\hline 1660 & Human & $19 \#$ & + & - & - & - & - & - & - & + & - & - & - & - \\
\hline 2948 & Human & $2 I^{\#}$ & - & - & - & - & - & - & - & - & - & - & - & - \\
\hline $81-178$ & Human [38] & $23,36 \#$ & + & - & + & + & + & - & - & + & - & - & - & - \\
\hline 1927 & Human & $31 \#$ & + & - & - & - & - & - & - & - & - & - & - & - \\
\hline 2462 & Chicken & $33 \#$ & + & - & - & - & - & - & - & - & - & - & - & - \\
\hline 2129 & Human & $37 \#$ & + & - & - & - & - & - & - & - & - & - & - & - \\
\hline 2144 & Human & $42^{\#}$ & + & - & - & - & - & - & - & + & - & - & - & - \\
\hline 1260 & Human & $53 \#$ & + & - & - & - & - & - & - & + & - & - & - & - \\
\hline 1680 & Chicken & $20^{\circ}$ & - & - & - & - & - & - & - & - & - & - & - & - \\
\hline 2476 & Chicken & $26^{a}$ & - & - & - & - & - & - & - & - & - & - & - & - \\
\hline 2454 & Food & $30^{\circ}$ & - & - & - & - & - & - & - & - & - & - & - & - \\
\hline 1669 & Human & $34^{a}$ & - & - & - & - & - & - & - & - & - & - & - & - \\
\hline 2458 & Chicken & $49^{a}$ & - & - & - & - & - & - & - & + & - & - & - & - \\
\hline 2474 & Chicken & $56^{\mathrm{a}}$ & - & - & - & - & - & - & - & - & - & - & - & - \\
\hline 2460 & Chicken & $59^{\circ}$ & - & - & - & - & - & - & - & - & - & - & - & - \\
\hline Total & 21 & 13 & 8 & 11 & 13 & 12 & 13 & 9 & 10 & 15 & 11 & 10 & & \\
\hline
\end{tabular}

$*+$, indicate positive reaction in the spot test;-, indicate negative reaction in the spot test.

nk, Not Known.

\# Belong to the $C$. jejuni sub species group

"Belong to the $C$. coli sub species group.

$\sim$ The serotype $4 c$ (4-complex) includes $C$. jejuni strains that reacts with one or more of the following antisera: 4, 13, 16, 43, 50, 64, 65 in the Penner serotyping system [9].

some correlation between phage sensitivity and serotype, especially for group II. However this correlation is not conclusive.

\section{Conclusion}

We have characterized and identified the host range of 12 Danish Campylobacter phages. Due to their ability to infect the common serotypes in Denmark we suggest the phages can become an effective agent in the effort to reduce the incidence of campylobacteriosis in Denmark. This study provides the basis for future experiments in Campylobacter phages, and knowledge for the selection of Campylobacter phages for biocontrol in broilers.

\section{Methods}

Campylobacter strains and cultures

Lawns of C. jejuni NCTC 12658 and NCTC 12662 from The National Collection of Type Cultures in the UK, and strain 1447, a Danish broiler isolate from our own strain collection, were used as hosts for phage isolation. A panel of 34 Penner serotyped Campylobacter strains were selected for host range testing. These comprised strains from a 
national surveillance study (11 strains from human feces, 16 strains from broiler feces, and two strains from chicken meat [8]). The remaining five Campylobacter strains were $11.168[36], 81-176[37,38]$, and the above mentioned strains used for phage isolation.

Unless specified, Campylobacter were cultured on agar at $41.5^{\circ} \mathrm{C}$ under microaerobic conditions $(5 \% \mathrm{O} 2,5 \% \mathrm{H} 2$, $10 \% \mathrm{CO} 2$, and $80 \% \mathrm{~N} 2$ ) and in broth cultures at $37^{\circ} \mathrm{C}$ under microaerobic conditions and stirring (250 rpm). Microaerobic environment was obtained in airtight jars by the evacuation and replacement technique (Anoxomat, Mart, Netherlands).

To prepare broth cultures, a colony was subcultured onto Colombia blood agar (C- calves blood II, Statens Serum Institut, DK) for $18 \mathrm{~h}$ and harvested into $\mathrm{NZCYMCaCl}_{2}$ broth ((21.98 g/l NZCYM-broth (Sigma)) supplemented with $1 \mathrm{mM} \mathrm{CaCl} 2$ (Sigma)). Optical density was adjusted to 0.1 at $600 \mathrm{~nm}$ followed by incubation for 100 minutes to allow for acclimatization of the cells.

\section{Sampling}

In the period July - September 2004 samples were obtained from five broiler slaughterhouses and one duck slaughterhouse in Denmark. Samples of abattoir waste water were collected into clean disposable jars from accessible points along the slaughter line. From selected poultry flocks two sets of intestines were randomly collected from each flock at the slaughterhouse and packed in plastic bags. It was requested that the selected flocks were Campylobacter positive. The samples were transported under chilled conditions to the test laboratory.

\section{Treatment of samples}

The content from two intestinal sets per flock were pooled and mixed 1: 5 with $\mathrm{NZCYMCaCl}_{2}$ broth and allowed to settle overnight at $4{ }^{\circ} \mathrm{C}$. The liquid phase was hereafter centrifuged $(11,000 \mathrm{~g}, 10 \mathrm{~min})$, and the supernatant syringe filtered $\left(0.20 \mu \mathrm{m}\right.$, Minisart $\left.{ }^{\circledast}\right)$ and stored in $50 \mathrm{ml}$ sterile centrifuge tubes (Sarstedt) at $4{ }^{\circ} \mathrm{C}$.

As regards to waste water samples, $50 \mathrm{ml}$ sample were centrifuged $(11,000 \mathrm{~g}, 10 \mathrm{~min})$ and the supernatant syringe filtered by a filter resistant to clogging $(0.20 \mu \mathrm{m}$, Corning 431218). To increase the likelihood of isolating phages from the diluted faecal material in the waste water, an enrichment procedure where implemented. $40 \mathrm{ml}$ of sample were enriched in $10 \mathrm{ml}$ of NZCYMx5 (109.9 g/l NZCYM broth (sigma)) and added $1 \mathrm{mM} \mathrm{CaCl} 2$ (Sigma) and $0.5 \mathrm{ml}$ broth culture (strain 1447 or NCTC 12662) prepared as described above. After incubation over night (125 rpm) one drop of chloroform was added to the enrichment cultures (Merck 1.02445), centrifuged (5000 $\mathrm{g}, 15 \mathrm{~min})$ and syringe filtered $(0.20 \mu \mathrm{m}$, Corning 431218).

\section{Isolation of phages}

Phages were detected by the plaque assay method. Double-layer plates were prepared as follows. In a $15 \mathrm{ml}$ centrifuge tube $0.1 \mathrm{ml}$ prepared broth culture of the host strain and $0.1 \mathrm{ml}$ pre-treated sample were mixed and absorption allowed for $15 \mathrm{~min}$ at $37^{\circ} \mathrm{C}$ followed by addition of $3 \mathrm{ml}$ soft agar (NZCYM broth added Agar-select 6 $\mathrm{g} / \mathrm{l}$, (Sigma)) $\left(50^{\circ} \mathrm{C}\right)$. The soft agar were poured onto a NZCYM plate (NZCYM broth added Agar-select $12 \mathrm{~g} / \mathrm{l}$ (Sigma) dried for $45 \mathrm{~min}$ in flow hood before use (minimum airflow, CleanLAF-o-matic, VFB 1206 BS)) and allowed to set for $15 \mathrm{~min}$ at room temperature on a plane surface before incubation for $18 \mathrm{~h}$. If the following inspection of the double-layer indicated plaques, material from a plaque was transferred by Pasteur pipette to $1 \mathrm{ml} \mathrm{SM}$ buffer (5.8 g NaCl (Merck), $2.0 \mathrm{~g} \mathrm{MgSO} 4$ *7H2O (Merck), Trizma ${ }^{\circledR}$ hydrochloride solution $50 \mathrm{ml}$ (Sigma), $5 \mathrm{ml}$ gelatin $2 \% \mathrm{w} / \mathrm{v}$ solution (Sigma), Milli-Q up to $1000 \mathrm{ml}[\mathrm{pH}$ $7,5]$. The phages were allowed to diffuse for $1 \mathrm{~h}$ at room temperature or over night at $4{ }^{\circ} \mathrm{C}$ before they were syringe filtered $(0.22 \mu \mathrm{m}$, Millipore, SLGV013SL). Prepared cultures of the strains C. jejuni NCTC 12662 and C. jejuni 1447 were used as host strains for all samples, whereas NCTC 12658 only were used for two samples.

\section{Treatment of phages}

Serial dilutions of each phage were prepared in SM-buffer for purification. Then $0.1 \mathrm{ml}$ of the dilution was mixed with $0.1 \mathrm{ml}$ prepared culture of the Campylobacter strain used for isolation. Absorption was allowed for $15 \mathrm{~min}$ before the mixture was embedded in soft agar as described above. A single plaque per sample was isolated after $18 \mathrm{~h}$ of incubation. Single plaque isolation was repeated three times prior to propagation to insure purity of the phages. The double-layer method was also used for propagation of the phages to obtain plates with confluent lysis. Confluent plates were flooded with $5 \mathrm{ml}$ of $\mathrm{NZCYMCaCl}$ broth and placed at $4{ }^{\circ} \mathrm{C}$ over night. The NZCYMCaCl${ }_{2}$ suspension was then transferred to a centrifuge tube and centrifuged (5000 g, $15 \mathrm{~min}$ ) prior to syringe filtering. The propagated phages were stored in cryotubes (Nunc) at $4^{\circ} \mathrm{C}$. Phage suspensions were titered on the isolation strain by plating serial phage dilutions $(0.1 \mathrm{ml})$ onto double-layer plates and counting plaques after $18 \mathrm{~h}$ of incubation. Concentration of the phage was determined as plaque-forming units (pfu) per $\mathrm{ml}$ on the strain used for isolation.

\section{Characterization of phage genomes}

For pulsed field gel electrophoresis (PFGE), phage suspensions $\left(10^{9} \mathrm{pfu} / \mathrm{ml}\right)$ were mixed $1: 1$ with $1.4 \%$ low melt agarose (Sigma, A-4018) and poured into molding blocks. 
DNA was liberated from the phage capsid by gently shaking the blocks overnight $\left(55^{\circ} \mathrm{C}, 100 \mathrm{rpm}\right)$ in $5 \mathrm{ml}$ lysis buffer (10 mM Tris (Merck, 108382), $100 \mathrm{mM}$ EDTA (Merck 1.08418) [pH 7.2], 1\% sarkosyl (Sigma, L5125), $0.1 \mathrm{mg} / \mathrm{ml}$ proteinase $\mathrm{K}$ (BioLab P8102S)). To stop the process blocks were washed for $20 \mathrm{~min}$ in $5 \mathrm{ml}$ washing buffer [50 mM EDTA, $20 \mathrm{mM}$ Tris] supplemented with 1 mM Phenylmethylsulfonylfluride (PMSF) (Sigma). The blocks were washed another 3 times in washing buffer without PMSF (Room temperature, 100 rpm). Blocks were kept at $4^{\circ} \mathrm{C}$ in TE-buffer [10 $\mathrm{mM}$ Tris, $1 \mathrm{mM}$ EDTA]. For PFGE, a $4 \mathrm{~mm}$ slice of a block was put in the well of a $1 \%$ agarose gel (BioRad 162-0137) and the well was sealed with $0.8 \%$ low melt agarose. PFGE marker \#N0340S or \#N0350S (New England Biolabs) were used as concatemer. The gel was run at $180 \mathrm{~V}, 14 \mathrm{~h}$, switch time $2-10 \mathrm{~s}$ in a Biorad CHEF II. The gel was stained with ethidium bromide for $10 \mathrm{~min}$ and washed in distilled water for 30 min before a photograph was taken.

For restriction endonuclease analysis (REA) a $4 \mathrm{~mm}$ slice of a block was cut and placed in HhaI (Biolab R0139S) in accordance with the manufacture's instructions. Then PFGE was done as described above.

\section{Electron microscopy imaging}

Based on genomic differences, six phages (F14, F198, F303, F325, F336, F341) were selected for transmission electron microscopy (TEM). Phages $\left(10^{8} \mathrm{pfu} / \mathrm{ml}\right)$ suspended in tris-buffer $(9.0 \mathrm{~g} / 1 \mathrm{NaCl}, 1.21 \mathrm{~g} / \mathrm{l}$ Trizma base [pH 7.4]) were centrifuged at $10,000 \mathrm{~g}$ for $20 \mathrm{~min}$ in a microcentrifuge. The pellet was resuspended in approx. 50 $\mu \mathrm{l}$ tris-buffer and a formvar carbon-coated grid was placed for $5 \mathrm{~min}$ on the surface of the particle suspension before being washed in two drops of $\mathrm{H}_{2} \mathrm{O}$ (Milli-Q, UltraPure). For negative staining the grid was placed for $2 \mathrm{~min}$ on a $2 \%$ sodium silicotungstate drop and air-dried before examination in a transmission electron microscope, $60 \mathrm{kV}$ (Zeiss EM 10).

\section{Test of host range}

Bacteria lawns were prepared by pouring $3 \mathrm{ml}$ NZCYM soft agar containing $0.1 \mathrm{ml}$ broth culture onto NZCYM plates. After the soft agar had solidified, plates were spotted manually with $10 \mu \mathrm{l}$ drops of phage suspensions on triplicate plates. Phage suspensions were adjusted to $10^{4}$ $10^{5}$ pfu per spot. NZCYMCaCl ${ }_{2}$ broth was used as negative control. The plates were allowed to dry for $15 \mathrm{~min}$ at room temperature before incubation. After 18-22 hours of incubation, the effect of the phage suspensions on the lawns were investigated. A positive response was defined as a number of $\geq 20$ plaques or full lysis (clear or opaque) in the spot.

\section{Authors' contributions}

$\mathrm{VMH}$ designed and carried out the microbiological and molecular work. SB conceived of the study and participated in its design. BBC and HRQ participated in its design with expert knowledge. DLB participated in the cordination and preliminary phase. $\mathrm{VMH}$ drafted the manuscript in collaboration with BBC and HRQ. All authores read and approved the final manuscript.

\section{Acknowledgements}

We thank Eva Moller Nielsen for kindly providing us with the serotyped Campylobacter strains, Annette Nygaard Jensen for serotyping of additional Campylobacter strains, Jane Nowicki for TEM imaging and Winnie Grebell for expert technical assistance. This work was supported by The Directorate for Food, Fisheries and Agri Business, Denmark.

\section{References}

I. Rosef O, Gondrosen B, Kapperud G, Underdal B: Isolation and characterization of Campylobacter jejuni and Campylobacter coli from domestic and wild mammals in Norway. Appl Environ Microbiol I 983, 46(4):855-59.

2. Shen Z, Feng F, Dewhirst FE, Fox JG: Coinfection of enteric Helicobacter spp. and Campylobacter spp. in cats. I Clin Microbiol 200I, 39(6):2I66-72.

3. European Food Safety Authority: Trends and sources of zoonoses, zoonotic agents and antimicrobial resistence in the European Union in 2004. The EFSA Journal 2006:2005-310.

4. Hald B, Pedersen K, Wainø M, Jørgensen JC, Madsen M: Longitudinal study of the excretion patterns of thermophilic Campylobacter Spp. in young pet dogs in Denmark. J Clin Microbiol 2004, 42(5):2003-2012.

5. Wingstrand A, Neimann J, Engberg J, Nielsen EM, Gerner-Smidt P, Wegener HC, Molbak K: Fresh chicken as main risk factor for campylobacteriosis, Denmark. Emerg Infect Dis 2006, I 2(2):280-5.

6. Kapperud G, Espeland G, Wahl E, Walde A, Herikstad H, Gustavsen $S$, Tveit I, Nata O, Bevanger L, Digranes A: Factors associated with increased and decreased risk of Campylobacter infection: a prospective case-control study in Norway. Am J Epidemiol 2003, I 58(3):234-42.

7. Neimann J, Engberg J, Molbak K, Wegner HC: A case-control study of risk factors for sporadic Campylobacter infections in Denmark. Epidemiol Infect 2003, I30(3):353-66.

8. Nielsen EM, Fussing V, Engberg J, Nielsen NL, Neimann J: Most Campylobacter subtypes from sporadic infections can be found in retail poultry products and food animals. Epidemiol Infect 2006, 134(4):758-767.

9. Anonymous: Campylobacter. In Agriculture and Fisheries ; 2004:18-20.

10. Rosenquist H, Nielsen NL, Sommer HM, Norrung B, Christensen BB: Quantitative risk assessment of human campylobacteriosis associated with thermophilic Campylobacter species in chickens. Int J Food Microbiol 2003, 83(I):87-103.

II. Havelaar AH, Nauta MJ, Mangen M-JJ, de Koeijer AG, Bogaardt M-J, Evers EG, Jacobs-Reitsma WF, van Pelt W, Wagenaar JA, de Wit GA, van der Zee $\mathrm{H}$ : Cost and benefits of controlling Campylobacter in the Netherlands, integrating risk analysis, epidemiology and economics. RIVM report 2509/1009/2005

12. Sandberg M, Hofshagen M, Østensvik $\varnothing$, Skjerve E, Innocent G: Survival of Campylobacter on frozen broiler carcasses as a function of time. J Food Prot 2005, 65(8): 1600-1605.

13. Georgsson F, Porkelsson AE, Geirsdóttir M, Reiersen J, Stern NJ: The influence of freezing and duration of storage on Campylobacter and indicator bacteria in broiler carcasses. Food Microbiol 2006, 23:677-683.

14. Rosenquist $\mathrm{H}$, Sommer HM, Nielsen NL, Christensen BB: The effect of slaughter operations on the contamination of chicken carcasses with thermotolerant Campylobacter. Int J Food microbiol 2006, 108:226-232

15. Greer GG: Bacteriophage control of foodborne bacteria. Food Prot 2005, 68(5): I I02-II. 
16. Huff WE, Huff GR, Rath NC, Balog JM, Donoghue AM: Alternatives to antibiotics: utilization of bacteriophage to colibacillosis and prevent foodborne pathogens. Poult Sci 2005, 84(4):655-9.

17. Grajewski BA, Kusek JW, Gelfand HM: Development of a phage typing for Campylobacter jejuni and Campylobacter coli. J Clin Microbiol 1985, 22(I): I3-I8.

18. Salama S, Bolton FJ, Hutchinson DN: Improved method for the isolation of Campylobacter jejuni and Campylobacter coli phages. Lett Appl Microbiol 1989, 8:5-7.

19. Khakheria R, Lior H: Extended phage-typing scheme for Campylobacter jejuni and Campylobacter coli. Epidemiol Infect | 992, 108:403-4|4

20. Atterbury RJ, Connerton PL, Dodd CE, Rees CE, Connerton IF: Isolation and characterization of Campylobacter bacteriophages from retail poultry. Appl Environ Microbiol 2003, 69(8):45 I I-8.

21. Connerton PL, Loc Carrillo CM, Swift C, Dillon E, Scott A, Rees CE, Dodd CE, Frost J, Connerton IF: Longitudinal study of Campylobacter jejuni bacteriophages and their hosts from broiler chickens. Appl Environ Microbiol 2004, 70(7):3877-83.

22. Atterbury RJ, Dillion E, Swift C, Connerton PL, Frost JA, Dodd CE, Rees CE, Connerton IF: Correlation of Campylobacter bacteriophage with reduced presence of hosts in broiler chicken ceca. Appl Environ Microbiol 2005, 7 I (8):4885-7.

23. El-Shibiny A, Connerton PL, Connerton IF: Enumeration and diversity of Campylobacters and bacteriophages isolated during the rearing cycles of free-range and organic chickens. Appl Environ Microbiol 2005, 7 I(3): I259-66.

24. Atterbury RJ, Connerton PL, Dodd CE, Rees CE, Connerton IF: Application of host-specific bacteriophages to the surface of chicken skin leads to a reduction in recovery of Campylobacter jejuni. Appl Environ Microbiol 2003, 69(10):6302-6.

25. Fiorentin L, Vieira ND, Barioni W Jr: Oral treatment with bacteriophages reduces the concentration of Salmonella Enteritidis PT4 in caecal contents of broilers. Avian Pathol 2005, 34(3):258-63.

26. Goode D, Allen VM, Barrow PA: Reduction of experimental Salmonella and Campylobacter contamination of chicken skin by application of lytic bacteriophages. Appl Environ Microbiol 2003, 69(8):5032-6

27. Higgins JP, Higgins SE, Guenther KL, Huff W, Donoghue AM, Donoghue DJ, Hargis BM: Use of a specific bacteriophage treatment to reduce Salmonella in poultry products. Poult Sci 2005 , 84(7): || $4 \mid-5$

28. Loc Carrillo C, Atterbury RJ, El-Shibiny A, Connerton PL, Dillon E, Scott A, Connerton IF: Bacteriophage therapy to reduce Campylobacter jejuni colonization of broiler chickens. Appl Environ Microbiol 2005, 7 I (I I):6554-6563.

29. Toro H, Price SB, McKee AS, Hoerr FJ, Krehling J, Perdue M, Bauermeister $L$ : Use of bacteriophages in combination with competitive exclusion to reduce Salmonella from infected chickens. Avian Dis 2005, 49(I): I 8-24.

30. Wagenaar JA, Van Bergen MA, Mueller MA, Wassenaar TM, Carlton RM: Phage therapy reduces Campylobacter jejuni colonization in broilers. Vet Microbiol 2005, 109:275-83.

31. Ackermann H-W, DuBow MS: Bacteriophage taxonomy. In Viruses of prokaryotes Volume I. Florida, Boca Raton: CRC Press, inc; 1987: 13-28.

32. Frost J, Kramer JM, Gillanders SA: Phage typing of Campylobacter jejuni and Campylobacter coli and its use as an adjunct to serotyping. Epidemiol Infect 1999, 1 23:47-55.

33. Sails AD, Wareing DRA, Bolton FJ, Fox AJ: Characterisation of 16 Campylobacter jejuni and $C$ coli typing bacteriophages. J Med Microbiol 1998, 47:123-128.

34. Coward C, Grant Al, Swift C, Philp J, Towler R, Heydarian M, Frost JA, Maskell DJ: Phase-variable surface structures are required for infection of Campylobacter jejuni by bacteriophages. Appl Environ Microbiol 2006, 72(7):4638-4647.

35. Karlyshev AV, Linton D, Gregson NA, Lastovica AJ, Wren BW: Genetic and biochemical evidence of Campylobacter jejun capsular polysaccharide that accounts for Penner serotype specificity. Mol Microbiol 2000, 35(3):529-54I.

36. Parkhill J, Wren BW, Mungall K, Ketley JM, Churcher C, Basham D, Chillingworth T, Davies RM, feltwell T, Holroyd S, Jagels K, Karlyshev AV, Moule S, Pallen MJ, Penn CW, Quail MA, Rajandream M-A, Rutherford KM, van Vliet AHM, Whitehead S, Barrell BG: The genome sequence of the food-borne pathogen Campylo- bacter jejuni reveals hypervariable sequences. Nature 2000 , 403:665-668

37. Black ER, Levine MM, Clements ML, Hughes TP, Blaser MJ: Experimental Campylobacter jejuni infection in humans. I Infect Dis 1988, 157(3):472-9.

38. Korlath JA, Osterholm MT, Judy LA, Forfang JC, Robinson RA: A point-source outbreak of campylobacteriosis associated with consumption of raw milk. J Infect Dis 1985, 152:592-6.
Publish with Bio Med Central and every scientist can read your work free of charge

"BioMed Central will be the most significant development for disseminating the results of biomedical research in our lifetime. "

Sir Paul Nurse, Cancer Research UK

Your research papers will be:

- available free of charge to the entire biomedical community

- peer reviewed and published immediately upon acceptance

- cited in PubMed and archived on PubMed Central

- yours - you keep the copyright
BioMedcentral 